\title{
LUMBAR SPINE, PELVIS, AND HIP SIT-TO-STAND ASSESSMENT PROTOCOLS AND ROM REFERENCE VALUES: A SYSTEMATIC REVIEW WITH META-ANALYSIS
}

review paper

( ) University School of Physical Education in Wroclaw

DOI: https://doi.org/10.5114/hm.2018.76074

\section{GRAZIELLE MARTINS GELAIN, EMANUELLE FRANCINE DETOGNI SCHMIT, PAULA VALENTE DE MESQUITA, CLAUDIA TARRAGO CANDOTTI}

Federal University of Rio Grande do Sul, Porto Alegre, Brazil

\begin{abstract}
Purpose. The evaluation of the sit-to-stand (STS) movement has been widely studied; however, very different protocols are used, making it difficult to choose a methodology. So, the purposes of this study were: (1) to identify the STS movement assessment protocols for lumbar spine, pelvis, or hip on the basis of video image analysis; (2) to investigate the reference values for these regions range of motion (ROM) using a systematic review with meta-analysis.

Methods. The searches were conducted in BIREME, Embase, PubMed, ScienceDirect, Scopus, and Web of Science databases; manual searches were also performed. Two independent reviewers selected the studies, extracted the data, and assessed the methodological quality and risk of bias. The methodological quality was verified by the Downs and Black scale and the strength of evidence by the GRADE system. Seventeen studies were included, from which data on sample, evaluation protocols, and ROM angles were extracted.

Results and conclusions. The studies showed high strength of evidence. Acquisition protocols diverged, but most of the studies utilized $3 \mathrm{D}$ video image analysis with optoelectronic systems, backless seat with adjustable height, and asking the subject to perform 3 trials of the movement in self-referred speed, keeping the arms crossed. The meta-analysis provided reference values for adults hip ROM (compared with the thigh) of 81.19-93.71 ${ }^{\circ}$. For the elderly, the angles for lumbar spine and hip position at the start of the STS movement were $0.20-3.99^{\circ}$ and $73.58-78.06^{\circ}$, respectively.
\end{abstract}

Key words: sit-to-stand, spine, pelvis, review

\section{Introduction}

The sit-to-stand (STS) movement represents one of the many functional activities and it is considered an ordinary and very representative task of the daily living [1]. Rising from the sitting position can be defined as a movement of transition to the erect posture through a change in the centre of body mass from a stable position to a less stable one. This movement ends with the extension of the lower limbs while the body keeps the balance on a small support base [2].

The analysis of the STS movement requires basic knowledge of the facts that influence its performance and phenomena determining the task completion. These are divided into 3 groups: related to the chair, related to the subject, and related to the strategy. The factors related to the chair comprise the seat height, the armrest, the backrest, and special chairs [3-5]. The factors related to the subject are age, illnesses, graduation of muscle strength, and utilization of shoes [6]. The factors related to the strategy come from the standing up movement: speed, feet position, utilization of the armrest, arms movement, joints stabilization in general, knee position, final restriction of movement, visual control, attention during the movement, training, position, and movement of the trunk [7, 8].

Kinematics is predominant among the most utilized movement assessment methods [1, 9, 10]; therefore, image analysis with a computer system is largely applied [8]. So, despite the variability of acquisition pro-

Correspondence address: Emanuelle Francine Detogni Schmit, BIOMEC - LAPEX Department, Federal University of Rio Grande do Sul, Rua Felizardo, 750 - Porto Alegre/RS CEP 90450-190 Brazil, e-mail: manu_schmit@hotmail.com

Received: September 4, 2017

Accepted for publication: April 6, 2018

Citation: Gelain GM, Schmit EFD, De Mesquita PV, Candotti CT. Lumbar spine, pelvis, and hip sit-to-stand assessment protocols and ROM reference values: a systematic review with meta-analysis. Hum Mov. 2018;19(3):3-15; doi: https://doi. org/10.5114/hm.2018.76074. 
G.M. Gelain, E.F.D. Schmit, P.V. De Mesquita, C.T.Candotti, STS protocols: review with meta-analysis

tocols for range of motion (ROM) for the lumbar spine, pelvis, or hip, there are no reference values for these variables. Besides, a great number of studies do not evaluate the role of the lumbar spine, pelvis, or hip in the STS movement [11]. Thus, the purposes of this study were to (1) identify the STS movement assessment protocols for lumbar spine, pelvis, or hip on the basis of video image analysis; (2) investigate the reference values for these regions ROM using a systematic review with meta-analysis.

\section{Material and methods}

\section{Study design}

The study presents a literature review directed by the PRISMA statement [12] in accordance with the recommendations of the Cochrane Collaboration and registered in the PROSPERO database (registration number: CRD42015029960, access link: http://www.crd. york.ac.uk/PROSPERO/display_record.asp?ID= CRD42015029960.

\section{Search strategies}

Systematic searches were conducted in accordance with the Cochrane Collaboration recommendations [13] in the BIREME, Embase, PubMed, ScienceDirect, Scopus, and Web of Science databases by the $21^{\text {st }}$ February, 2017. The keywords used and the respective Boolean operators were Spine [OR] Pelvis [AND] Sit-to-stand. The strategy to search the PubMed database is visualized in Table 1 . The date of publication was not restricted, but the languages were limited to English, Spanish, and Portuguese. Moreover, some studies identified in the references were also included in the screening.

Two independent reviewers selected the potentially relevant studies after reading titles and abstracts. When an abstract contained not enough information, the entire article was read. After this, the same reviewers independently screened the full studies, selecting them in accordance with the eligibility criteria: (1) design observational study or clinical trial; (2) kinematic evaluation of the ROM and angular values for the lumbar spine, pelvis, or hip through video analysis; (3) evaluation of sitting down, standing up, or both movements; (4) evaluation of healthy subjects; (5) language: Brazilian Portuguese, Spanish, or English. Discrepancies were resolved by consensus and, when necessary, a third reviewer was included [14].

Data extraction, quality assessment, and risk of bias

Only included studies underwent data extraction, quality appraisal, and risk of bias analysis. The second phase, data extraction, was performed independently by the same reviewers, and discrepancies were resolved by consensus. Information was extracted with a standardized form and included: first author's name, publication year, participants (healthy subjects), assessment protocol, and variables of interest (Tables 2-5).

The methodological quality of the included studies was evaluated by the Downs and Black checklist, which consists of 27 items and attributes 1 point to a study when the answer to the criteria is yes and the item is fulfilled, or 0 points when the answer is no and the item is not fulfilled. The checklist is an adaptable instrument that can assess observational studies and clinical trials besides presenting reproducibility and internal consistency; those were the reasons why it was chosen. All items must be considered in the assessment of clinical trials. However, in this review, only observational studies were included and only 12 items of the checklist were taken into account (Table 6). The studies were ascribed high methodological quality if they fulfilled at least $60 \%$ of the items considered in the assessment. As previously, in this third step, the methodological quality was determined independently by the same 2 reviewers and discrepancies were resolved by consensus.

Table 1. Strategy to search the PubMed database

\#4 Search (\#1 OR \#2 AND \#3)

\#3 Search ('Sit-to-stand' OR 'Stand-to-sit' OR 'Sit to stand' OR 'Stand to sit' OR 'Sitting to standing' OR 'Sit-to-stance-to-sit' OR 'Sitting' OR 'Sit-stand-sit' OR 'Back-to-sit' OR 'Pattern of movement')

\#2 Search ('Pelvis’[Mesh] OR ‘Pelvis’ OR ‘Pelvic Region’ OR ‘Region, Pelvic’)

\#1 Search ('Spine’[Mesh] OR ‘Spine’ OR ‘Vertebral Column’ OR ‘Column, Vertebral’ OR ‘Columns, Vertebral’ OR

'Vertebral Columns’ OR 'Spinal Column’ OR ‘Column, Spinal’ OR ‘Columns, Spinal’ OR ‘Spinal Columns’)

Study inclusion 


\section{Statistical analysis}

Data were analysed by descriptive statistics and divided in subgroups with the consideration of the angular variable, video image analysis, and methodology. The meta-analysis was performed with the MedCalc Statistical Software v. 18 (MedCalc Software, Ostend, Belgium) by inputting mean and standard error. The Higgins' test of inconsistency $\left(I^{2}\right)$ was applied to evaluate inter-studies heterogeneity and the result was considered low if $I^{2}<50 \%$ or moderate/high if $I^{2} \geq 50 \%$ [12].

\section{Strength of evidence}

The GRADE (Grading of Recommendations Assessment, Development and Evaluation) system was utilized to rate the quality of evidence and recommendation strength provided by the systematic review. It considers the following criteria for the studies included: study design, methodological limitations, inconsistency (homogeneity of the studies), direct evidence, results' accuracy, existence of publication bias for not including the totality of published studies concerning the issue of research [15].

On the basis of the criteria established, the GRADE system classifies the evidence level as: high quality additional research will very unlikely change the results presented by the systematic review; moderate quality - further research will probably cause important impact and could change the results presented by the systematic review; low quality - further research will very likely cause impact and will probably alter the results presented by the systematic review; very low quality - any estimate of the results presented by the systematic review is uncertain and requires new studies.

\section{Results}

In the databases searched, 4751 studies were found and 21 studies were included by manual searches. Duplicates (2561) were removed and 2211 studies had the title and the abstract screened. In this phase, 2161 studies did meet the eligibility criteria and the rest of 50 studies were read entirely. Only 17 studies fulfilled all the eligibility criteria and were included in the review. Figure 1 shows the flow diagram of inclusion stages in accordance with the PRISMA recommendations [12].

Tables 2 and 3 summarize the main STS and STS/ stand-to-assessment protocols found in the included studies $(n=17)$. Tables 5 and 6 show the angular values and ROM for lumbar spine, pelvis, and hip. The score of the methodological quality presented by the studies is

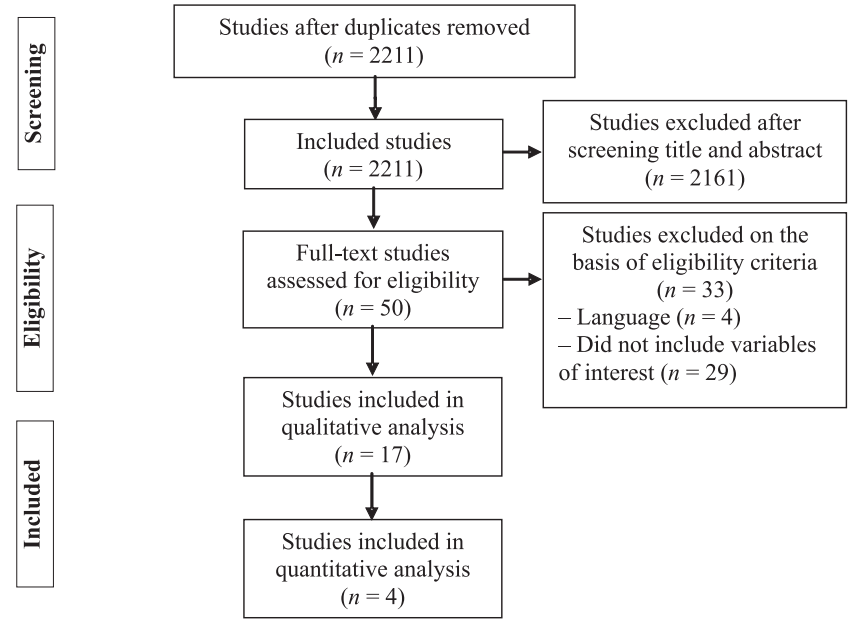

Figure 1. Flow of information through the different phases of the systematic review with meta-analysis in accordance with the PRISMA recommendations [12]

depicted in Table 6. All included articles had a crosssectional study design.

On the basis of the assessment of the overall quality of evidence for the 17 involved studies, $12 \%(n=2)$ scored low quality. Also, taking into account the heterogeneity of the studies regarding the methodological rigor, only 4 studies could be included in the metaanalysis (Tables 7-12). So, further research is likely to have an important impact on the outcomes of this review and may change the results found for the angular values and ROM reference values of lumbar spine, pelvis, and hip during the STS and STS/standto-sit movements. In this way, in agreement with the GRADE rating, this review has moderate quality of evidence [15].

\section{Discussion}

With the purpose of helping the choice among the STS assessment protocols for the lumbar spine, pelvis, or hip regions, some important issues need to be taken into consideration.

Video image analysis and performance parameters

The 3D systems guarantee precise quantification of true spatial movements because they eliminate the perspective error, but the procedures and analyses are more complicated and demand more equipment requisites [30]. However, the option for validated 2D systems can be interesting [31]. Also, frequency rates above $100 \mathrm{~Hz}$ are desirable because they assure capturing minimum linear and angular shifts in a joint 


\section{HUMAN MOVEMENT}

G.M. Gelain, E.F.D. Schmit, P.V. De Mesquita, C.T.Candotti, STS protocols: review with meta-analysis

Table 2. Protocols used to evaluate the movement of standing up from the sitting position (indexed by video image analysis and by author)

\begin{tabular}{|c|c|c|c|}
\hline $\begin{array}{l}1^{\text {st }} \text { author } \\
\text { (year) and } \\
\text { sample (age } \\
\text { range, years) } \\
\end{array}$ & $\begin{array}{l}\text { Video image analysis } \\
\text { and performance parameters }\end{array}$ & $\begin{array}{c}\text { Movement phases and description } \\
\text { of angular measurement }\end{array}$ & $\begin{array}{c}\text { Anatomical landmarks (for lumbar, } \\
\text { pelvic, and hip variables) }\end{array}$ \\
\hline $\begin{array}{l}\text { Anan } \\
(2008)[17] \\
n=11 \\
(79-87)\end{array}$ & $\begin{array}{l}\text { - } 2 \text { D - } 1 \text { camera, NHI Image (30 frames/s) } \\
\text { - Backless seat: head of fibula height } \\
\text { - Vertical shanks } \\
\text { - Barefoot subjects } \\
\text { - Medial border of the feet } 40^{\circ} \\
\text { - Crossed arms } \\
\text { - Look forward instruction, no visual target } \\
\text { - } 3 \text { trials (those considered symmetrical by } \\
\text { subject and evaluator) } \\
\text { - } 4 \text { sitting conditions: no cushion }(0 \mathrm{~mm}), 30-\text {, } \\
60 \text {-, and } 90 \text {-mm height cushion }\end{array}$ & $\begin{array}{l}\text { - Complete STS movement } \\
\text { - Pelvic angle in relation to the horizontal } \\
\text { plane } \\
\text { - Hip angle in relation to the horizontal } \\
\text { plane }\end{array}$ & $\begin{array}{l}\text { Unilateral: } \\
\text { - acromion } \\
\text { - the lowest rib } \\
\text { - ASIS/PSIS } \\
\text { - greater trochanter } \\
\text { - lateral knee joint line }\end{array}$ \\
\hline $\begin{array}{l}\text { Fotoohabadi } \\
(2010)[11] \\
n=41 \\
(64-75)\end{array}$ & $\begin{array}{l}\text { - } 2 \text { D - } 1 \text { camera, Peak Motus system } \\
\text { - Backless seat with adjustable height: } 100 \% \\
\text { shank height } \\
\text { - Barefoot subjects } \\
\text { - Feet position: back/forward defined } \\
\text { by the subject } \\
\text { - Crossed arms } \\
\text { - } 3 \text { trials } \\
\text { - Only the 'smoothest' trial was analysed } \\
\text { - Self-selected speed }\end{array}$ & $\begin{array}{l}\text { - Start: } 10 \% \text { increase in the horizontal } \\
\text { displacement of the T1 marker } \\
\text { - Seat-off : } 10 \% \text { increase in the vertical } \\
\text { displacement of the proximal } 2 / 3 \text { thigh } \\
\text { marker } \\
\text { - End: the point of no further hip extension } \\
\text { - Lumbar angle: angle between the line } \\
\text { defined by T11-L1 and the line perpendicular } \\
\text { to the pelvic plane }{ }^{\text {a }} \\
\text { - Hip angle: between the long axis of the femur } \\
\text { ( } 2 / 3 \text { thigh-supracondylar markers) and the } \\
\text { pelvic plane }\end{array}$ & $\begin{array}{l}\text { Unilateral: } \\
\text { - T11, L1 } \\
\text { - ASIS/PSIS } \\
\text { - proximal } 2 / 3 \text { thigh } \\
\text { - above the lateral condyle } \\
\text { of the femur }\end{array}$ \\
\hline $\begin{array}{l}\text { Tully } \\
(2005)[18] \\
n=47 \\
(18-30)\end{array}$ & $\begin{array}{l}\text { - } 2 \text { D - } 1 \text { camera, Peak Motus system (50 } \\
\text { frames/s) } \\
\text { - Backless seat with height adjustable: shank } \\
\text { length (mid-line knee) } \\
\text { - Barefoot subjects } \\
\text { - Crossed arms } \\
\text { - Self-selected speed } \\
\text { - Repeated until performance without } \\
\text { unwanted or unnatural actions }\end{array}$ & $\begin{array}{l}\text { - Start: with the horizontal displacement } \\
\text { of the T1 marker } \\
\text { - Seat-off: } 10 \% \text { of the vertical displacement } \\
\text { of the proximal ( } 2 / 3 \mathrm{Th}) \text { thigh marker } \\
\text { - End: maximal vertical displacement } \\
\text { of the T1 marker } \\
\text { - Lumbar angle: angle between the line } \\
\text { defined by T11-L1 and the line } \\
\text { perpendicular to the pelvic plane } \\
\text { - Hip angle: between the long axis of the } \\
\text { femur ( } 2 / 3 \text { thigh-supracondylar markers) } \\
\text { and the pelvic plane }{ }^{\text {a }}\end{array}$ & $\begin{array}{l}\text { Unilateral: } \\
\text { - L1 } \\
\text { - } 3 \text { cm proximal to L1 } \\
\text { Bilateral: } \\
\text { - ASIS/PSIS } \\
\text { - } 2 / 3 \text { thigh } \\
\text { - supracondylar thigh }\end{array}$ \\
\hline $\begin{array}{l}\text { Gilleard } \\
(2008)[19] \\
n=12 \\
(24-33)\end{array}$ & $\begin{array}{l}\text { - } 3 \mathrm{D} \text { - } 8 \text { cameras, Expert Vision }(60 \mathrm{~Hz}) \\
\text { - Seat height: } 110 \% \text { of fibular head distance } \\
\text { to the floor } \\
\text { - Arms beside the body } \\
\text { - Visual target } \\
\text { - } 3 \text { trials, repeated on } 3 \text { occasions } 16 \text { weeks } \\
\text { - Apart } \\
\text { - Self-selected speed }\end{array}$ & $\begin{array}{l}\text { - Start: the horizontal velocity of the great } \\
\text { humeral tubercle marker was } \geqslant 10 \mathrm{~mm} / \mathrm{s} \\
\text { and the marker did not move in the vertical } \\
\text { direction } \\
\text { - Seat-off: maximum right posterior ground } \\
\text { reaction force } \\
\text { - End: maximal knee extension and maximal } \\
\text { vertical displacement of the right great } \\
\text { humeral tubercle marker } \\
\text { - Hip: midpoint between left and right ASIS } \\
\text { and left and right PSIS }\end{array}$ & $\begin{array}{l}\text { Bilateral: } \\
\text { - ASIS/PSIS } \\
\text { - apex of sacrum } \\
\text { - subtrochanter } \\
\text { - mid thigh (10 cm above the patella) } \\
\text { - lateral femoral epicondyle }\end{array}$ \\
\hline $\begin{array}{l}\text { Cacciatore } \\
(2011)[20] \\
n=30 \\
15 \text { ATT } \\
(33-51) \\
15 \text { controls } \\
(38-48)\end{array}$ & $\begin{array}{l}\text { - } 3 \mathrm{D} \text { - } 7 \text { cameras, Falcon }(60 \mathrm{~Hz}) \\
\text { - Backless seat } \\
\text { - Seat height: } 105^{\circ} \text { shank height } \\
\text { - Knee } 85^{\circ} \text { flexion } \\
\text { - Crossed arms } \\
\text { - } 5 \text { trials } \\
\text { - Self-selected speed }\end{array}$ & $\begin{array}{l}\text { - Phase Ia: flexion only } \\
\text { - Phase Ib: began when the force applied } \\
\text { on the feet exceeded } 30 \% \text { of bodyweight } \\
\text { - Phase II (momentum-transfer): between } \\
\text { the instant when the force applied on the } \\
\text { feet was } 100 \% \text { of bodyweight and the } \\
\text { max Өankle } \\
\text { - Phase III: between max Өankle and when } \\
\text { Otrunk reached } 5^{\circ} \text { of its value during stance } \\
\text { - Angles compared with the initial seated value } \\
\text { - Lumbar angle }=\mathrm{L} 1+\mathrm{L} 4\end{array}$ & $\begin{array}{l}\text { Bilateral: } \\
\text { - greater trochanter } \\
\text { - lateral knee epicondyle } \\
\text { - L1, L4 } \\
\text { - midpoint of the sacral crest }\end{array}$ \\
\hline $\begin{array}{l}\text { Burnfield } \\
(2012)[3] \\
n=10 \\
(18-23)\end{array}$ & $\begin{array}{l}\text { - } 3 \mathrm{D} \text { - } 12 \text { cameras, Qualisys }(120 \mathrm{~Hz}) \\
\text { - Backless seat with adjustable height } \\
\text { ( } 45.72 \mathrm{~cm} / 18 \text { inches }) \\
\text { - Relaxed arms } \\
\text { - Number of trials not informed } \\
\text { - Self-selected speed }\end{array}$ & $\begin{array}{l}\text { - Complete STS movement } \\
\text { - Pelvis angle: related to vertical plane } \\
\text { - Hip compared with the thigh }\end{array}$ & $\begin{array}{l}\text { Unilateral (right side): } \\
\text { - greater trochanter } \\
\text { - medial and lateral femoral condyles } \\
\text { Bilateral: } \\
\text { - acromion } \\
\text { - iliac crests } \\
\text { - ASIS/PSIS }\end{array}$ \\
\hline
\end{tabular}




\begin{tabular}{|c|c|c|c|}
\hline $\begin{array}{l}\text { Johnson } \\
(2010)[21] \\
n=24 \\
\text { (mean: } 26.5)\end{array}$ & $\begin{array}{l}\text { - 3D - } 6 \text { cameras, Qualisys }(100 \mathrm{~Hz}) \\
\text { - Backless seat: } 85 \% \text { knee height } \\
\text { - Arms beside the body } \\
\text { - Greater trochanters } 4 \mathrm{~cm} \text { from the seat edge } \\
\text { - Face forward } \\
\text { - Barefoot subjects; comfortable feet position } \\
\text { marked with tape } \\
\text { - } 4 \text { trials of } 6 \text { seconds }\end{array}$ & $\begin{array}{l}\text { - Complete STS movement } \\
\text { - Lumbar spine ROM in relation to the pelvis } \\
\text { - Hip ROM in relation to the thigh }\end{array}$ & $\begin{array}{l}\text { Unilateral: } \\
\text { - lumbar } \\
\text { Bilateral: } \\
\text { - pelvis } \\
\text { - thighs }\end{array}$ \\
\hline $\begin{array}{l}\text { Johnson } \\
(2010)[22] \\
n=32 \\
\text { (mean: } 27)\end{array}$ & $\begin{array}{l}\text { - } 3 \mathrm{D} \text { - } 6 \text { cameras, Qualisys }(100 \mathrm{~Hz}) \\
\text { - Backless seat: } 100 \% \text { knee height } \\
\text { - } 85^{\circ} \text { knee flexion } \\
\text { - Greater trochanters } 4 \mathrm{~cm} \text { from the seat edge } \\
\text { - Barefoot subjects } \\
\text { - Feet position marked with tape } \\
\text { - } 5 \text { trials of } 6 \text { seconds }\end{array}$ & $\begin{array}{l}\text { - Complete STS movement } \\
\text { - Lumbar spine ROM in relation to the pelvis } \\
\text { - Hip ROM in relation to the thigh }\end{array}$ & $\begin{array}{l}\text { Unilateral: } \\
\text { - lumbar } \\
\text { Bilateral: } \\
\text { - pelvis } \\
\text { - thighs }\end{array}$ \\
\hline $\begin{array}{l}\text { Ikeda } \\
(1991)[23] \\
n=18 \\
9 \text { young } \\
(25-36) \\
9 \text { elderly } \\
(61-74)\end{array}$ & $\begin{array}{l}\text { - } 3 \mathrm{D}-4 \text { cameras, Selspot II }(150 \mathrm{~Hz}) \\
\text { - Backless seat: } 80 \% \text { knee height } \\
\text { - Barefoot subjects } \\
\text { - Feet } 10.16 \mathrm{~cm} \text { apart and parallel } \\
\text { - Crossed arms } \\
\text { - } 2 \text { trials } \\
\text { - Speed of } 52 \mathrm{bpm} \\
\end{array}$ & $\begin{array}{l}\text { - Phase I: began with hip or trunk flexion } \\
\text { velocity } \\
\text { - Phase II: began with seat-off of the buttocks } \\
\text { - Phase III: began with maximal dorsiflexion } \\
\text { and ended with hip extension velocity of } 0 \\
\text { - Phase IV: terminal hip extension } \\
\text { - Hip: not explained }\end{array}$ & $\begin{array}{l}\text { Unilateral: } \\
\text { - trunk } \\
\text { Bilateral: } \\
\text { - pelvis } \\
\text { - thighs }\end{array}$ \\
\hline $\begin{array}{l}\text { Schenkman } \\
(1990)[24] \\
n=9 \\
(25-36)\end{array}$ & $\begin{array}{l}\text { - } 3 \mathrm{D} \text { - } 4 \text { cameras, Selspot II }(153 \mathrm{~Hz}) \\
\text { - Backless seat: } 80 \% \text { of knee height } \\
\text { - Barefoot subjects } \\
\text { - Feet } 10.16 \mathrm{~cm} \text { apart } \\
\text { - Crossed arms } \\
\text { - } 2 \text { trials } \\
\text { - Speed of } 52 \mathrm{bpm} \\
\end{array}$ & $\begin{array}{l}\text { - Phase I: initiation of the movement } \\
\text { - Phase II: seat-off } \\
\text { - Phase III: began with maximum dorsiflexion } \\
\text { - Phase IV: the hip ceased to extend } \\
\text { - Hip: not explained }\end{array}$ & $\begin{array}{l}\text { Bilateral: } \\
\text { - legs } \\
\text { - thighs } \\
\text { - pelvis } \\
\text { - trunk }\end{array}$ \\
\hline $\begin{array}{l}\text { Anan } \\
(2015)[6] \\
n=17 \\
(65-74)\end{array}$ & $\begin{array}{l}\text { - 3D - } 6 \text { infrared cameras, Vicon (100 frames/s) } \\
\text { - Backless seat } \\
\text { - Vertical shanks } \\
\text { - Crossed arms } \\
\text { - Barefoot subjects } \\
\text { - Feet apart (distance between ASIS) } \\
\text { - Look forward instruction, no visual target } \\
\text { - } 5 \text { trials } \\
\text { - Self-selected speed }\end{array}$ & $\begin{array}{l}\text { - Phase I: start to seat-off } \\
\text { - Phase II: seat-off to the end of motion } \\
\text { - Pelvic angle: relative to the global space }\end{array}$ & $\begin{array}{l}\text { Bilateral: } \\
\text { - acromion } \\
\text { - inferior edge of the last rib } \\
\text { - superior edge of the iliac crest } \\
\text { - ASIS/PSIS } \\
\text { - greater trochanter } \\
\text { - lateral/medial epicondyle } \\
\text { of the femur }\end{array}$ \\
\hline $\begin{array}{l}\text { Kinoshita } \\
(2015)[25] \\
n=16 \\
(21-43)\end{array}$ & $\begin{array}{l}\text { - } 3 \mathrm{D} \text { - } 7 \text { cameras, Vicon }(100 \mathrm{~Hz}) \\
\text { - } 90^{\circ} \text { knee flexion } \\
\text { - Crossed arms } \\
\text { - } 3 \text { trials } \\
\text { - Self-selected speed }\end{array}$ & $\begin{array}{l}\text { - Complete STS movement } \\
\text { - Hip angle: calculation not informed } \\
\text { - Angles compared with the initial seated value }\end{array}$ & $\begin{array}{l}\text { Bilateral: } \\
\text { - mid-distance between the neck and } \\
\text { the lateral aspect of the shoulder } \\
\text { - ASIS/PSIS } \\
\text { - } 3 \text { markers laterally on the thigh } \\
\end{array}$ \\
\hline $\begin{array}{l}\text { Kim } \\
(2014)[26] \\
n=16 \\
(20-23)\end{array}$ & $\begin{array}{l}\text { - } 3 \mathrm{D} \text { - } 6 \text { cameras, Vicon }(100 \mathrm{~Hz}) \\
\text { - Backless seat height: distance from } \\
\text { the mid-knee-joint line to the floor } \\
\text { - } 90^{\circ} \text { knee flexion } \\
\text { - Crossed arms } \\
\text { - } 3 \text { trials } \\
\text { - } 1 \text {-minute pause }\end{array}$ & $\begin{array}{l}\text { - Complete STS movement } \\
\text { - Pelvic angle: in relation to the ground } \\
\text { - Lumbar angle: in relation to the pelvis } \\
\text { - Hip angle: in relation to the pelvis }\end{array}$ & $\begin{array}{l}\text { Unilateral: } \\
\text { - T12, L1 } \\
\text { Bilateral: } \\
\text { - ASIS/PSIS } \\
\text { - lateral thigh } \\
\text { - lateral malleoli } \\
\text { - } 3 \mathrm{~cm} \text { to the left and to the right } \\
\text { of L1 }\end{array}$ \\
\hline $\begin{array}{l}\text { Leardini } \\
(2011)[27] \\
n=10 \\
(23-26)\end{array}$ & $\begin{array}{l}\text { - } 3 \mathrm{D} \text { - } 8 \text { cameras, Vicon }(100 \mathrm{~Hz}) \\
\text { - Backless seat height: tibia perpendicular } \\
\text { to the floor } \\
\text { - } 90^{\circ} \text { flexion for hip and knees } \\
\text { - Parallel feet } \\
\text { - Relaxed arms } \\
\text { - Number of trials not informed } \\
\text { - Self-selected speed }\end{array}$ & $\begin{array}{l}\text { - Complete STS movement } \\
\text { - Joint angles compared with adjacent } \\
\text { segments: } \\
\text { - L1 in relation to L3 } \\
\text { - L3 in relation to L5 } \\
\text { - L5 in relation to the pelvis }\end{array}$ & $\begin{array}{l}\text { Unilateral: } \\
\text { - L1, L3, L5 } \\
\text { Bilateral: } \\
\text { - acromion } \\
\text { - suprasternal notch } \\
\text { - ASIS/PSIS } \\
\text { - xiphoid process } \\
\text { - mid-point between the inferior } \\
\text { angles of scapulae }\end{array}$ \\
\hline $\begin{array}{l}\text { Park } \\
(2014)[28] \\
n=12 \\
(20-27)\end{array}$ & $\begin{array}{l}-3 \mathrm{D} \text { - } 8 \text { cameras, Vicon }(100 \mathrm{~Hz}) \\
\text { - } 2 \text { trials } \\
\text { - Self-selected speed } \\
\text { - } 3 \text {-minute practice before trials } \\
\text { - } 1 \text {-minute rest prior to trials }\end{array}$ & $\begin{array}{l}\text { - Complete STS movement } \\
\text { - Pelvic angle: calculated as the difference } \\
\text { between the maximal pelvic flexion angle } \\
\text { and the initial pelvic angle }\end{array}$ & $\begin{array}{l}\text { Bilateral: } \\
\text { - ASIS/PSIS } \\
\text { - lateral epicondyle of the femur } \\
\text { - lateral thigh }\end{array}$ \\
\hline
\end{tabular}

a Pelvic plane - the line joining PSIS to ASIS

ASIS - anterior superior iliac spine, ATT - Alexander Technique teachers, PSIS - posterior superior iliac spine,

ROM - range of motion, STS - sit-to-stand 


\section{HUMAN MOVEMENT}

G.M. Gelain, E.F.D. Schmit, P.V. De Mesquita, C.T.Candotti, STS protocols: review with meta-analysis

Table 3. Protocols used to evaluate sit-to-stand and stand-to-sit movements (standing up from the sitting position and back to sitting) (indexed by video image analysis and by author)

\begin{tabular}{|c|c|c|c|}
\hline $\begin{array}{l}1^{\text {st }} \text { author } \\
\text { (year) and } \\
\text { sample (age } \\
\text { range, years) }\end{array}$ & $\begin{array}{c}\text { Video image analysis and performance } \\
\text { parameters }\end{array}$ & $\begin{array}{l}\text { Movement phases and description } \\
\text { of angular measurement }\end{array}$ & Anatomical references markers \\
\hline $\begin{array}{l}\text { Kuo } \\
(2010)[5] \\
n=32 \\
(60-75)\end{array}$ & $\begin{array}{l}\text { - } 2 \text { D - } 1 \text { camera, Peak system } \\
\text { - Backless seat } \\
\text { - } 2 \text { seat heights: } 100 \% \text { and } 80 \% \text { of knee } \\
\text { height } \\
\text { - Barefoot subjects } \\
\text { - Foot position preferred by subject not } \\
\text { changing during trials } \\
\text { - Crossed arms } \\
\text { - } 3 \text { trials } \\
\text { - Only the 'smoothest' trial was analysed } \\
\text { - Self-selected speed }\end{array}$ & $\begin{array}{l}\text { - Start/end: the resultant linear velocity } \\
\text { of the T1 marker greater or smaller } \\
\text { than } 1 \mathrm{~cm} / \mathrm{s} \\
\text { - Seat-off: } 10 \% \text { increase of the normalized } \\
\text { vertical displacement of the proximal } \\
\text { thigh marker } \\
\text { - Lumbar angle: angle between the } \\
\text { line defined by T11-L1 and the line } \\
\text { perpendicular to the pelvic plane } \\
\text { - Hip angle: between the long axis of the } \\
\text { femur (2/3 thigh-supracondylar markers) } \\
\text { and the pelvic plane }\end{array}$ & $\begin{array}{l}\text { Unilateral (right side): } \\
\text { - L1, S2 } \\
\text { - T3 and T11 estimated during } \\
\text { analysis } \\
\text { - suprasternal notch } \\
\text { - ASIS/PSIS } \\
\text { - } 2 / 3 \text { thigh } \\
\text { - } 1 / 4 \text { thigh }\end{array}$ \\
\hline $\begin{array}{l}\text { Nuzik } \\
(1986) \text { [29] } \\
n=55 \\
(20-48)\end{array}$ & $\begin{array}{l}\text { - } 2 \mathrm{D} \text { - } 1 \text { Bolex camera }(32 \mathrm{frames} / \mathrm{s}) \\
\text { - Backless seat height: } 46 \mathrm{~cm} \\
\text { - Feet position: back/forward defined } \\
\text { by the subject } \\
\text { - Relaxed arms on thighs } \\
\text { - } 3 \text { trials } \\
\text { - Only one trial analysed according to } \\
\text { criteria } \\
\text { - Self-selected speed }\end{array}$ & $\begin{array}{l}\text { - Sit-to-stand and back to sitting were } \\
\text { analysed as a single movement } \\
\text { - Pelvic angle: the line between the } \\
\text { greater trochanter and the mid-iliac } \\
\text { crest perpendicular to the horizontal } \\
\text { plane } \\
\text { - Hip angle: the lateral femoral epicondyle, } \\
\text { the greater trochanter, and the mid-iliac } \\
\text { crest }\end{array}$ & $\begin{array}{l}\text { Unilateral: } \\
\text { - acromion } \\
\text { - mid-iliac crest } \\
\text { - greater trochanter } \\
\text { - lateral femoral epicondyle }\end{array}$ \\
\hline
\end{tabular}

a Pelvic plane - the line joining PSIS to ASIS

ASIS - anterior superior iliac spine, PSIS - posterior superior iliac spine

or limb, as well as recording the key events of standing up and sitting down performance [32].

In relation to the seat attributes, all studies included in this review utilized a stool, that is, a structure without a backrest or armrest. A support for the upper limbs reduces the load over knees and hips and also decreases by $50 \%$ the moment of extension necessary to rise up from the sitting position [8]. Still, according to Janssen et al. [8], the backrest is a strategy to standardize the initial position of standing up. Such strategies condition the subject to a position that may differ from their habitual posture, so the authors assume that the movement will not represent the natural and reliable execution [8]. Concerning the seat height, to establish a fixed height means, for example, to increase hips and knees flexion of taller subjects in a way that the standing up movement becomes much more exigent or even impossible [8]. It is known that adjusting the seat from $115 \%$ to $65 \%$ of the knee height increases by almost $100 \%$ the angular speed of the trunk flexion in young adults to reach the stand position [33].

The position of the arms impacts on the displacement of the centre of mass because these segments move forward during motion [8]. For this reason, the study of the STS movement restricts the use of the arms despite their being a common support for elderly and young adults [25, 34]. However, restricting the arms position considerably alters the angular displacement of the ankle, requiring more adjustments of this joint to reach the standing posture [7]. Also, the position of the feet influences the movement, as confirmed by Shepherd and Koh [35], who studied the positioning of the feet in the STS movement and showed that a posterior feet position reduced the total speed of movement and that an anterior positioning increased the time of the pre-extension phase. However, no electromyographic difference was found in the muscle groups of the lower limbs between the normal and posterior position of the feet [36].

In relation to the execution speed, subjects prevented from accomplishing the task in the self-selected speed in order to increase reproducibility may not act naturally, and so the execution will not be spontaneous or representative. The self-selected speed strategy seeks an execution closer to the habitual pattern and thus more reliable. Also, the number of trials for analysing the STS movement is diverse in literature, but the reliability (intraclass correlation coefficient of 0.67-0.94) and validity of 5 STS trials were confirmed and it is the most common number of repetitions applied [37]. 

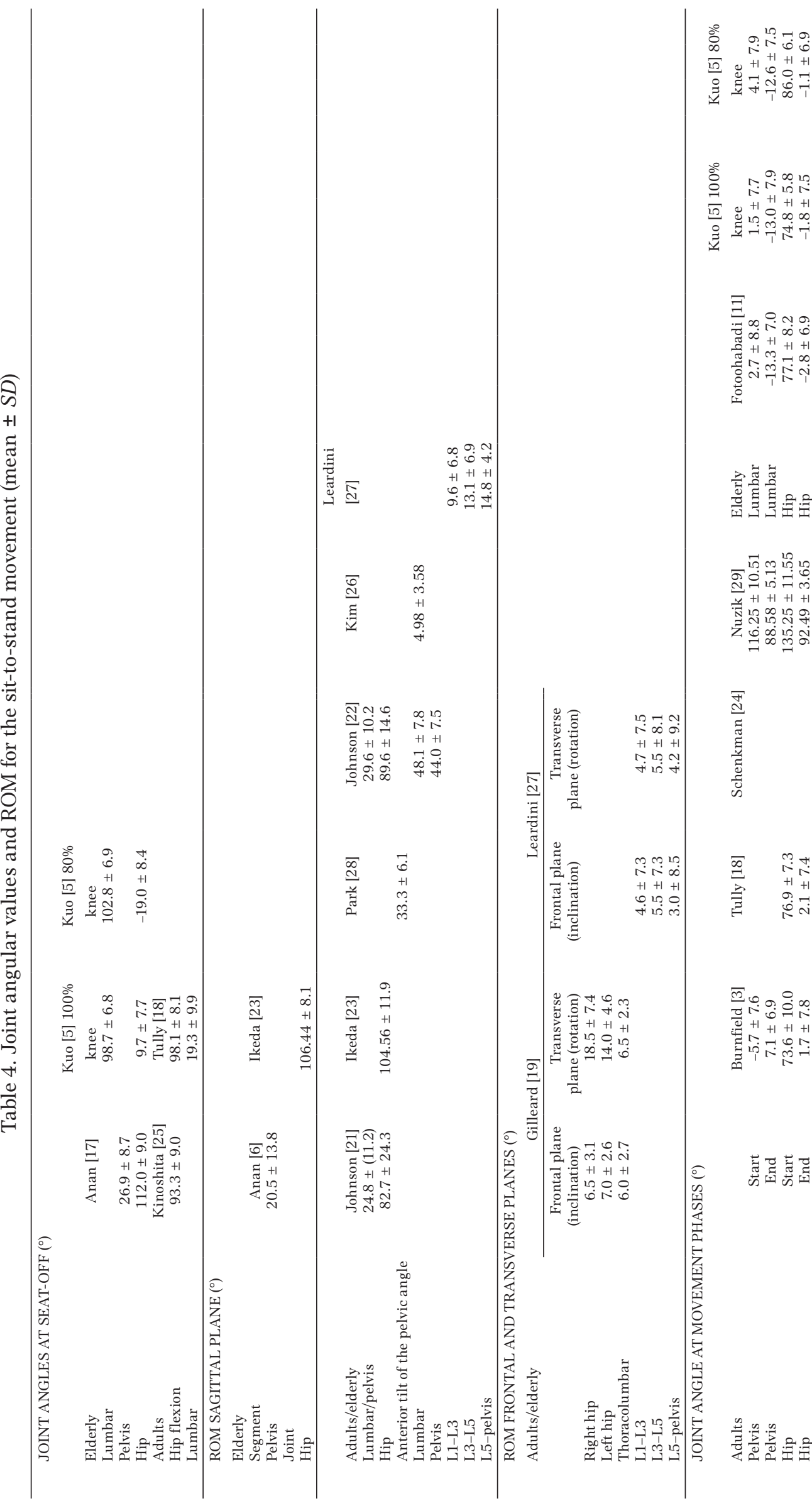

롤

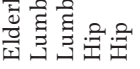

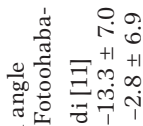

퐁ำ

$2+1+1+1+1$

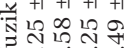

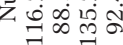

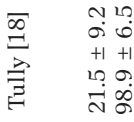

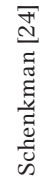

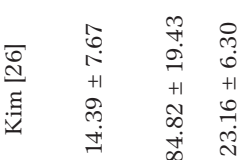

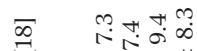

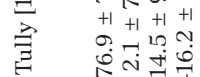

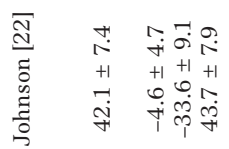

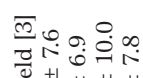

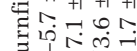

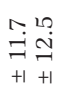

莫节

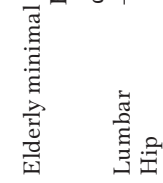

两

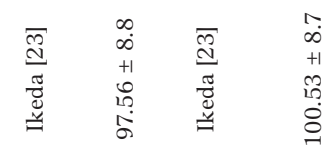

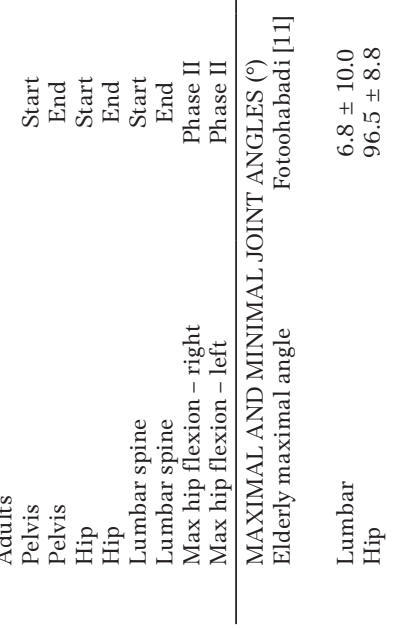

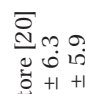

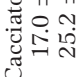

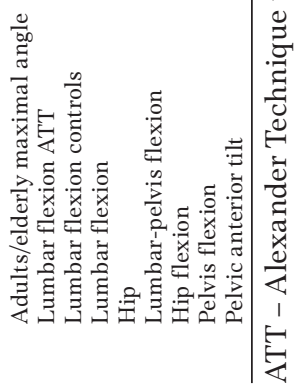




\section{HUMAN MOVEMENT}

G.M. Gelain, E.F.D. Schmit, P.V. De Mesquita, C.T.Candotti, STS protocols: review with meta-analysis

Table 5. Joint angular values and ROM for the movements of sit-to-stand and stand-to-sit (mean $\pm S D)$

\begin{tabular}{|c|c|c|c|}
\hline \multicolumn{4}{|c|}{ ROM SAGITTAL PLANE, SIT-TO-STAND AND STAND-TO-SIT $\left(^{\circ}\right)$} \\
\hline Adults and elderly & Kuo [5] 100\% knee & Kuo [5] 80\% knee & \\
\hline Lumbar spine & $23.9 \pm 6.9$ & $33.4 \pm 8.7$ & \\
\hline Hip & $101.2 \pm 6.9$ & $105.0 \pm 8.7$ & \\
\hline \multicolumn{4}{|c|}{ MAXIMAL AND MINIMAL JOINT ANGLES $\left(^{\circ}\right)$} \\
\hline Adults & Kuo [5] 100\% knee & Kuo [5] 80\% knee & \\
\hline Lumbar & $10.6 \pm 7.2$ & $20.3 \pm 7.8$ & \\
\hline Hip & $99.5 \pm 6.7$ & $103.8 \pm 6.5$ & \\
\hline \multicolumn{4}{|c|}{ JOINT ANGLE AT MOVEMENT PHASES $\left(^{\circ}\right)$} \\
\hline Elderly & & Kuo [5] 100\% knee & Kuo [5] 80\% knee \\
\hline Lumbar & Start & $1.5 \pm 7.7$ & $4.1 \pm 7.9$ \\
\hline Lumbar & Seat-off & $9.0 \pm 7.7$ & $19.0 \pm 8.4$ \\
\hline Lumbar & End & $-13.0 \pm 7.9$ & $-12.6 \pm 7.5$ \\
\hline Hip & Start & $74.8 \pm 5.8$ & $86.0 \pm 6.1$ \\
\hline Hip & Seat-off & $98.7 \pm 6.8$ & $102.8 \pm 6.9$ \\
\hline Hip & End & $-1.8 \pm 7.5$ & $-1.1 \pm 6.9$ \\
\hline Adults & & Nuzik [29] & \\
\hline Pelvis & Start & $116.25 \pm 10.51$ & \\
\hline Pelvis & End & $88.58 \pm 5.13$ & \\
\hline Hip & Start & $135.25 \pm 11.55$ & \\
\hline Hip & End & $92.49 \pm 3.65$ & \\
\hline
\end{tabular}

$\mathrm{ROM}$ - range of motion

Table 6. Studies scores of methodological quality appraisal in accordance with Downs and Black [16] scale

\begin{tabular}{|c|c|c|c|c|c|c|c|c|c|c|c|c|c|c|c|c|}
\hline First author (year) & 1 & 2 & 3 & & 5 & 7 & 9 & 10 & 11 & 12 & 16 & 18 & 20 & $\begin{array}{l}\text { No. } \\
\text { of } \sqrt{ }\end{array}$ & $\begin{array}{c}\text { Quality } \\
(\%)\end{array}$ & $\begin{array}{l}\text { High } \\
\text { quality }\end{array}$ \\
\hline \multicolumn{17}{|c|}{ Standing up from the sitting position } \\
\hline Anan (2008) [17] & $\sqrt{ }$ & $\sqrt{ }$ & $\sqrt{ }$ & $\sqrt{ }$ & $\sqrt{ }$ & $\sqrt{ }$ & $\mathrm{x}$ & & $\mathrm{x}$ & $\mathrm{x}$ & $\sqrt{ }$ & $\sqrt{ }$ & $\sqrt{ }$ & 9 & 75.0 & Yes \\
\hline Anan (2015) [6] & $\sqrt{ }$ & $\sqrt{ }$ & $\sqrt{ }$ & $\sqrt{ }$ & $\sqrt{ }$ & $\sqrt{ }$ & $\mathrm{x}$ & & $\mathrm{x}$ & $\mathrm{x}$ & $\sqrt{ }$ & $\sqrt{ }$ & $\mathrm{x}$ & 8 & 66.7 & Yes \\
\hline Burnfield (2012) [3] & $\sqrt{ }$ & $\sqrt{ }$ & $\sqrt{ }$ & $\sqrt{ }$ & $\sqrt{ }$ & $\sqrt{ }$ & $\mathrm{x}$ & & $\mathrm{x}$ & $\mathrm{x}$ & $\sqrt{ }$ & $\sqrt{ }$ & $\mathrm{x}$ & 8 & 66.7 & Yes \\
\hline Cacciatore (2011) [20] & $\sqrt{ }$ & $\sqrt{ }$ & $\sqrt{ }$ & $\sqrt{ }$ & $\sqrt{ }$ & $\sqrt{ }$ & $\sqrt{ }$ & & $\mathrm{x}$ & $\mathrm{x}$ & $\sqrt{ }$ & $\sqrt{ }$ & $\mathrm{x}$ & 9 & 75.0 & Yes \\
\hline Fotoohabadi (2010) [11] & $\sqrt{ }$ & $\sqrt{ }$ & $\sqrt{ }$ & $\sqrt{ }$ & $\sqrt{ }$ & $\sqrt{ }$ & $\sqrt{ }$ & & $\mathrm{x}$ & $\mathrm{x}$ & $\sqrt{ }$ & $\sqrt{ }$ & $\sqrt{ }$ & 10 & 83.3 & Yes \\
\hline Gilleard (2008) [19] & $\sqrt{ }$ & $\sqrt{ }$ & $\sqrt{ }$ & $\sqrt{ }$ & $\sqrt{ }$ & $\sqrt{ }$ & $\sqrt{ }$ & & $\mathrm{x}$ & $\mathrm{x}$ & $\sqrt{ }$ & $\sqrt{ }$ & $\sqrt{ }$ & 10 & 83.3 & Yes \\
\hline Ikeda (1991) [23] & $\sqrt{ }$ & $\sqrt{ }$ & $\sqrt{ }$ & $\sqrt{ }$ & $\sqrt{ }$ & $\sqrt{ }$ & $\mathrm{x}$ & & $\mathrm{x}$ & $\mathrm{x}$ & $\sqrt{ }$ & $\mathrm{x}$ & $\mathrm{x}$ & 7 & 58.3 & No \\
\hline Johnson (2010) [21] & $\sqrt{ }$ & $\sqrt{ }$ & $\sqrt{ }$ & $\sqrt{ }$ & $\sqrt{ }$ & $\sqrt{ }$ & $\sqrt{ }$ & & $\mathrm{x}$ & $\mathrm{x}$ & $\sqrt{ }$ & $\sqrt{ }$ & $\mathrm{x}$ & 9 & 75.0 & Yes \\
\hline Johnson (2010) [22] & $\sqrt{ }$ & $\sqrt{ }$ & $\sqrt{ }$ & $\sqrt{ }$ & $\sqrt{ }$ & $\sqrt{ }$ & $\sqrt{ }$ & & $\mathrm{x}$ & $\mathrm{x}$ & $\sqrt{ }$ & $\sqrt{ }$ & $\mathrm{x}$ & 9 & 75.0 & Yes \\
\hline Kinoshita (2015) [25] & $\sqrt{ }$ & $\sqrt{ }$ & $\sqrt{ }$ & $\sqrt{ }$ & $\sqrt{ }$ & $\sqrt{ }$ & $\sqrt{ }$ & & $\mathrm{x}$ & $\mathrm{x}$ & $\sqrt{ }$ & $\sqrt{ }$ & $\sqrt{ }$ & 10 & 83.3 & Yes \\
\hline Kim (2014) [26] & $\sqrt{ }$ & $\sqrt{ }$ & $\sqrt{ }$ & $\sqrt{ }$ & $\sqrt{ }$ & $\sqrt{ }$ & $\sqrt{ }$ & & $\mathrm{x}$ & $\mathrm{x}$ & $\sqrt{ }$ & $\sqrt{ }$ & $\mathrm{x}$ & 9 & 75.0 & Yes \\
\hline Leardini (2011) [27] & $\sqrt{ }$ & $\sqrt{ }$ & $\sqrt{ }$ & $\sqrt{ }$ & $\sqrt{ }$ & $\sqrt{ }$ & $\mathrm{x}$ & & $\mathrm{x}$ & $\mathrm{x}$ & $\sqrt{ }$ & $\mathrm{x}$ & $\sqrt{ }$ & 8 & 66.7 & Yes \\
\hline Park (2014) [28] & $\sqrt{ }$ & $\sqrt{ }$ & $\sqrt{ }$ & $\sqrt{ }$ & $\sqrt{ }$ & $\sqrt{ }$ & $\mathrm{x}$ & & $\mathrm{x}$ & $\mathrm{x}$ & $\sqrt{ }$ & $\sqrt{ }$ & $\mathrm{x}$ & 8 & 66.7 & Yes \\
\hline Schenkman (1990) [24] & $\sqrt{ }$ & $\sqrt{ }$ & $\sqrt{ }$ & $\sqrt{ }$ & $\sqrt{ }$ & $\sqrt{ }$ & $\mathrm{x}$ & & $\mathrm{x}$ & $\mathrm{x}$ & $\sqrt{ }$ & $\sqrt{ }$ & $\mathrm{x}$ & 8 & 66.7 & Yes \\
\hline Tully (2005) [18] & $\sqrt{ }$ & $\sqrt{ }$ & $\sqrt{ }$ & $\sqrt{ }$ & $\sqrt{ }$ & $\sqrt{ }$ & $\mathrm{x}$ & & $\mathrm{x}$ & $\mathrm{x}$ & $\sqrt{ }$ & $\sqrt{ }$ & $\mathrm{x}$ & 8 & 66.7 & Yes \\
\hline \multicolumn{17}{|c|}{ Stand-to-sit and sit-to-stand movements } \\
\hline Kuo (2010) [5] & $\sqrt{ }$ & $\sqrt{ }$ & $\sqrt{ }$ & $\sqrt{ }$ & $\sqrt{ }$ & $\sqrt{ }$ & $\sqrt{ }$ & & $\mathrm{x}$ & $\mathrm{x}$ & $\sqrt{ }$ & $\sqrt{ }$ & $\sqrt{ }$ & 10 & 83.3 & Yes \\
\hline Nuzik (1986) [29] & $\sqrt{ }$ & $\sqrt{ }$ & $\sqrt{ }$ & $\mathrm{x}$ & $\sqrt{ }$ & $\sqrt{ }$ & $\mathrm{x}$ & & $\mathrm{x}$ & $\mathrm{x}$ & $\sqrt{ }$ & $\mathrm{x}$ & $\mathrm{x}$ & 6 & 50.0 & No \\
\hline
\end{tabular}

(1) Is the objective and hypothesis of the study clearly described? (2) Are the main outcomes to be measured clearly described in the introduction or materials and methods section? (3) Are the characteristics of the subjects included in the study clearly described? (6) Are the main findings of the study clearly described? (7) Does the study provide estimates of the variability in the data for the main outcomes? (9) Are the characteristics of participants lost to follow-up described? (10) Are actual probability values reported for the main outcomes? (11) Were the subjects asked to participate in the study representative of the entire population from which they were recruited? (12) Were those subjects who were prepared to participate representative of the entire population from which they were recruited? (16) If any of the results of the study is based on 'data dredging,' is this made clear? (18) Were statistical tests used to assess the main outcomes appropriate? (20) Are the main outcome measures used accurate? Answers to the criteria: $\sqrt{ }-$ yes, $\mathrm{x}-$ no. 
Movement phases and description of angular measurement

Etnyre and Thomas [38], in their study on determining STS motion phases, suggest that there can be 6 vertical events (initiation of movement, counter-force prior to seat-off, the seat-off, the peak force, the postpeak rebound force, and the final steady standing force), 3 horizontal events (the start of force, the peak force, and the end of force), and 2 lateral events (right and left forces). Most of the studies in literature do not evaluate the transverse or frontal planes. So, the standardization of the phases or events of the movement is essential to establish parameters of comparison. Furthermore, it is important to mention that measuring speed and force requires more sophisticated evaluation tools, such as force plates, accelerometers, or force transducers. This technology, while sensitive to small changes in STS performance, is hardly available in clinical settings, besides making data analysis more complex [39].

\section{Anatomical references markers}

The anatomical landmarks diverge vastly and their positioning can bias the results. Kuo et al. [40], in their study on measurement errors due to skin movement, compared the markers located on the thigh between the model that identified the major trochanter and lateral epicondyle of the femur and the model that calculated the position of the marker in $2 / 3$ of the thigh and $1 / 4$ of the thigh (the distance between the greater trochanter and the mid-lateral knee joint was measured along the mid-lateral thigh, and the $2 / 3$ and $1 / 4$ markers were positioned at the corresponding distances). Their main finding was that the trochanterepicondyle model underestimated the sagittal angle of the hip, while the $2 / 3$ proximal $-1 / 4$ distal thigh model provided a more accurate measurement of sagittal hip angle throughout the full available range of hip flexion. Skin movement on the pelvis had a small counterbalancing effect on the larger errors from lateral thigh markers, thereby decreasing hip angle error. Yet, Turcot et al. [41], to avoid the displacement of the markers on the skin, used rigid clusters with 3 markers on the thighs and legs. So, still there is no consensus over the landmarks utilized for the STS evaluation.

\section{Angular values of normality}

Meta-analyses have been performed to identify angular values of normality for the lumbar spine (Tables 7, 9, and 10) and hip (Tables 8, 11, and 12) for both

Table 7. Meta-analysis results for the lumbar spine range of motion $\left(^{\circ}\right)$ in relation to the pelvic plane in adult population (21-34 years)

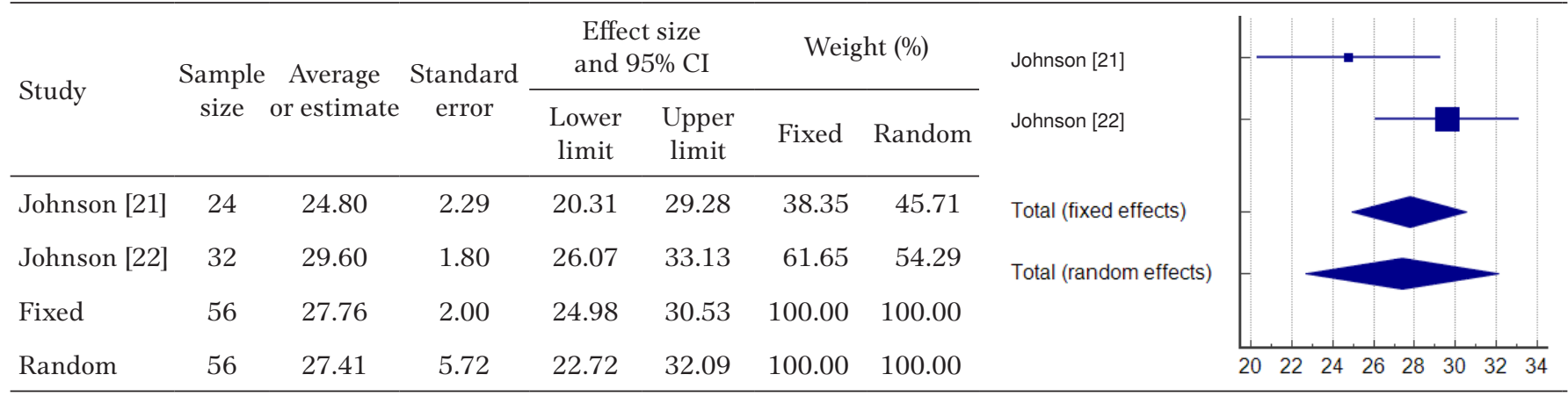

Heterogeneity: $Q=2.72 ; D F=1 ; p=0.099 ; I^{2}=63.21 \%$

Table 8. Meta-analysis results for the hip range of motion $\left(^{\circ}\right)$ in relation to the thigh in adult population (21-34 years)

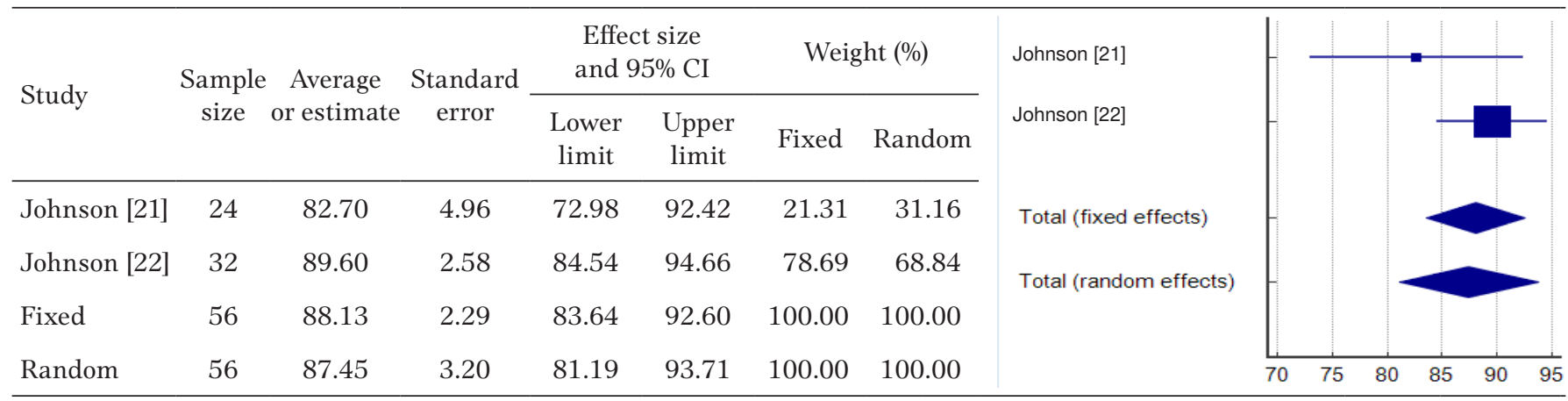

Heterogeneity: $Q=1.52 ; D F=1 ; p=0.217 ; I^{2}=34.33 \%$ 


\section{HUMAN MOVEMENT}

G.M. Gelain, E.F.D. Schmit, P.V. De Mesquita, C.T.Candotti, STS protocols: review with meta-analysis

Table 9. Meta-analysis results for the lumbar spine angle $\left(^{\circ}\right)$ at the start of the sit-to-stand movement in elderly population (60-75 years)

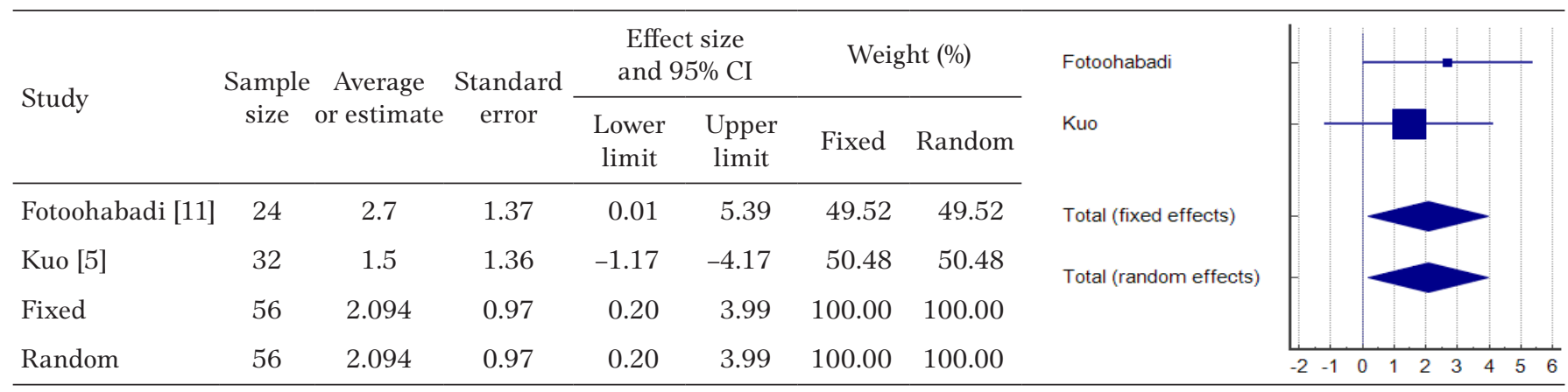

Heterogeneity: $Q=0.39 ; D F=1 ; p=0.535 ; I^{2}=0.00 \%$

Table 10. Meta-analysis results for the lumbar spine angle $\left(^{\circ}\right)$ at the seat-off moment in elderly population (60-75 years)

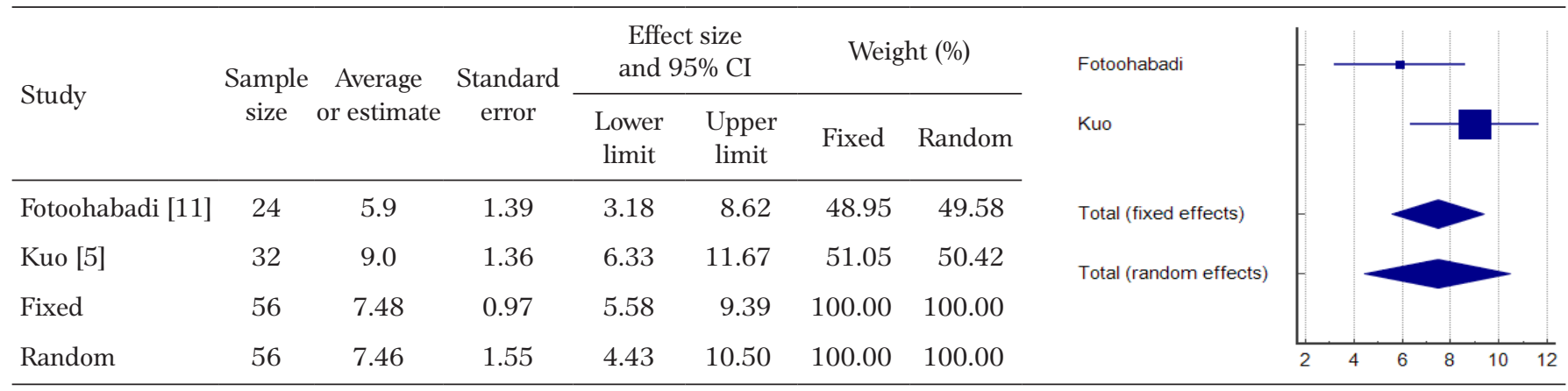

Heterogeneity: $Q=2.54 ; D F=1 ; p=0.111 ; I^{2}=60.62 \%$

Table 11. Meta-analysis results for the hip angle $\left(^{\circ}\right)$ at the start of the sit-to-stand movement in elderly population (60-75 years)

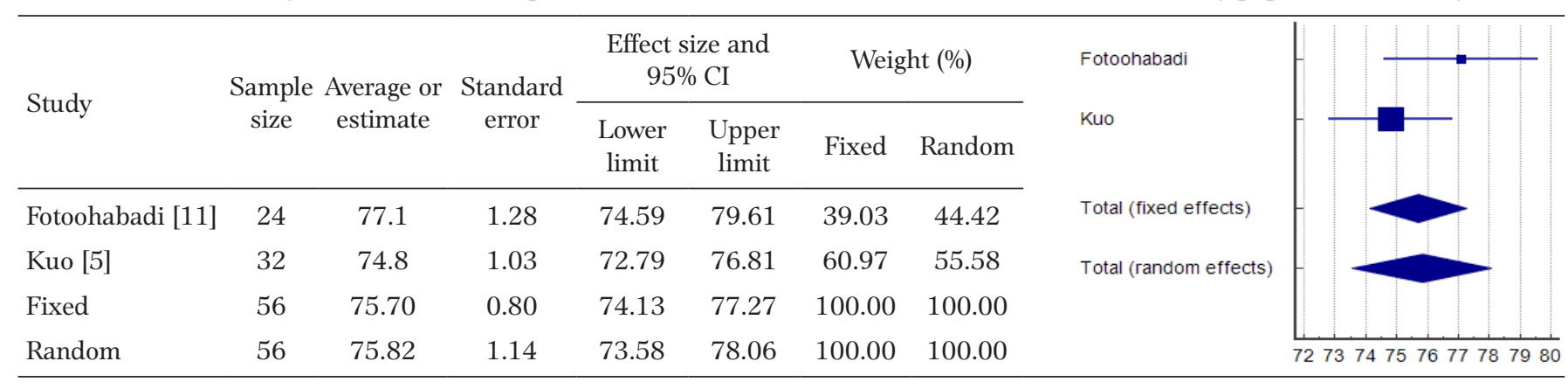

Heterogeneity: $Q=1.97 ; D F=1 ; p=0.161 ; I^{2}=49.12 \%$

Table 12. Meta-analysis results for the hip angle $\left(^{\circ}\right)$ at the seat-off moment in elderly population (60-75 years)

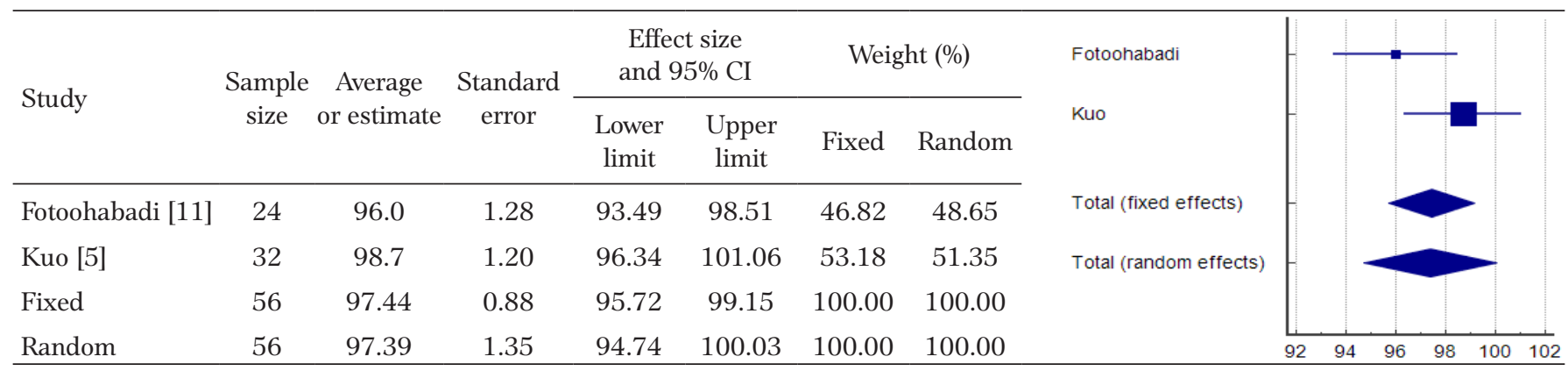

Heterogeneity: $Q=2.36 ; D F=1 ; p=0.124 ; I^{2}=57.67 \%$ 
adult and elderly population. The results allow to indicate the values of normality only for the ROM of the hip relative to the thigh $\left(81.19-93.71^{\circ}\right)$ in the adult population (Table 8 ). It was also possible to identify reference values for the elderly population only for the angular value of the hip in relation to the thigh (73.58$78.06^{\circ}$ ) and for the angular value of the lumbar spine in relation to the pelvic plane $\left(0.20-3.99^{\circ}\right)$, both at the exact initiation of the STS movement while in the seated position (Tables 11 and 9, respectively).

A limitation of this study is the absence of the evaluation of the coordination between the joints (lumbar, pelvis, and hip) in order to understand motor control and compensation mechanism. Therefore, this factor could be included in future research, similarly as the peripheral sensation and comfort sensation. For this purpose, further studies, especially comparative ones, could include the assessment of the subjective discomfort perception with scales such as the modified Schechter scale [42]. Also, populations with specific pathologies or injuries could be investigated.

\section{Conclusions}

The STS assessment protocols diverge greatly from the location of anatomical markers to the positioning of the subject and the parameters of movement. In summary, it was possible to observe that most of the studies made use of video cameras with optoelectronic systems of 3-dimensional image analysis, in the range of $100-153 \mathrm{~Hz}$, opting for backless seats with height adjustable to the extension of the individuals' legs. Also, in most of the studies, the subjects were asked to perform 3 repetitions of the movement at a self-selected speed, keeping the arms crossed. However, considering that this review presents a moderate quality of evidence, on the basis of the GRADE criteria, it is suggested that the parameters of the STS evaluation protocol be carefully defined by each researcher in accordance with their objectives.

Concerning the reference values for ROM and angular variables determined for the lumbar spine, pelvis, and hip with video analysis, it can be stated that for the adult population the normality values for the hip ROM, in relation to the thigh plane, vary between $81.19^{\circ}$ and $93.71^{\circ}$. Also, at the very start of the STS movement, in the elderly population, the reference angular value of the lumbar spine relative to the pelvic plane varies from $0.20^{\circ}$ to $3.99^{\circ}$, while the reference angle of the hip relative to the thigh plane ranges from $73.58^{\circ}$ and $78.06^{\circ}$. Nevertheless, considering the heterogeneity of the included studies, it is possible that further research may change the results for the angular values of normality found for the STS movement.

\section{Disclosure statement}

No author has any financial interest or received any financial benefit from this research.

\section{Conflict of interest}

The authors state no conflict of interest.

\section{References}

1. Bonnet V, Azevedo-Coste C, Robert T, Fraisse P, Venture G. Optimal external wrench distribution during a multi-contact sit-to-stand task. IEEE Trans Neural Syst Rehabil Engineering. 2017;25(7):987-997; doi: 10.1109/TNSRE.2017.2676465.

2. Vander Linden DW, Brunt D, McCulloch MU. Variant and invariant characteristics of the sit-to-stand task in healthy elderly adults. Arch Phys Med Rehabil. 1994;75(6):653-660.

3. Burnfield JM, Shu Y, Buster TW, Taylor AP, McBride MM, Krause ME. Kinematic and electromyographic analyses of normal and device-assisted sit-to-stand transfers. Gait Posture. 2012;36(3):516-522; doi: 10.1016/j. gaitpost.2012.05.002.

4. Kuo FC, Hong CZ, Liau BY. Kinematics and muscle activity of the head, lumbar and knee joints during $180^{\circ}$ turning and sitting down task in older adults. Clin Biomech. 2014;29(1):14-20; doi: 10.1016/j.clinbiomech.2013.10.020.

5. Kuo YL, Tully EA, Galea MP. Kinematics of sagittal spine and lower limb movement in healthy older adults during sit-to-stand from two seat heights. Spine. 2010; 35(1):E1-E7; doi: 10.1097/BRS.0b013e3181c47a0e.

6. Anan M, Shinkoda K, Suzuki K, Yagi M, Ibara T, Kito N. Do patients with knee osteoarthritis perform sit-tostand motion efficiently? GaitPosture. 2015;41(2):488492; doi: 10.1016/j.gaitpost.2014.11.015.

7. Blache Y, Pairot de Fontenay BP, Monteil K. The effects of seat height and foot placement on lumbar spine load during sit-to-stand tasks. Ergonomics. 2014;57(11): 1687-1695; doi: 10.1080/00140139.2014.948495.

8. Janssen WG, Bussmann HB, Stam HJ. Determinants of the sit-to-stand movement: a review. Phys Ther. 2002; 82(9):866-879; doi: 10.1093/ptj/82.9.866.

9. Hemming R, Sheeran L, van Deursen R, Sparkes V. Evaluating sagittal spinal posture during functional tasks: can kinematics differentiate between non-specific chronic low back pain (NSCLBP) subgroups and healthy controls? Eur Spine J. 2015;24(Suppl 6):S752.

10. Christe G, Redhead L, Legrand T, Jolles BM, Favre J. Multi-segment analysis of spinal kinematics during sit-to-stand in patients with chronic low back pain. J Biomech. 2016;49(10):2060-2067; doi: 10.1016/j.jbiomech.2016.05.015. 
G.M. Gelain, E.F.D. Schmit, P.V. De Mesquita, C.T.Candotti, STS protocols: review with meta-analysis

11. Fotoohabadi MR, Tully EA, Galea MP. Kinematics of rising from a chair: image-based analysis of the sagittal hip-spine movement pattern in elderly people who are healthy. Phys Ther. 2010;90(4):561-571; doi: 10.2522/ptj.20090093.

12. Moher D, Liberati A, Tetzlaff J, Altman DG. Preferred reporting items for systematic reviews and meta-analyses: the PRISMA statement. PLoS Med. 2009;6(7): e1000097; doi: 10.1371/journal.pmed.1000097.

13. Higgins JPT, Green S (eds.). Cochrane handbook for systematic reviews of interventions. Hoboken: John Wiley \& Sons; 2011.

14. Van Tulder MW, Koes BW, Bouter LM. Conservative treatment of acute and chronic nonspecific low back pain. A systematic review of randomized controlled trials of the most common interventions. Spine. 1997;22(18): 2128-2156; doi: 10.1097/00007632-199709150-00012.

15. Guyatt G, Oxman AD, Akl EA, Kunz R, Vist G, Brozek J, et al. GRADE guidelines: 1. Introduction-GRADE evidence profiles and summary of findings tables. J Clin Epidemiol. 2011;64(4):383-394; doi: 10.1016/j.jclinepi.2010.04.026.

16. Downs SH, Black N. The feasibility of creating a checklist for the assessment of the methodological quality both of randomised and non-randomised studies of health care interventions. J Epidemiol Community Health. 1998; 52(6):377-384.

17. Anan M, Okumura K, Kito N, Shinkoda K. Effects of variation in cushion thickness on the sit-to-stand motion of elderly people. J Phys Ther Sci. 2008;20(1):51-57; doi: 10.1589/jpts.20.51.

18. Tully EA, Fotoohabadi MR, Galea MP. Sagittal spine and lower limb movement during sit-to-stand in healthy young subjects. Gait Posture. 2005;22(4):338-345; doi: 10.1016/j.gaitpost.2004.11.007.

19. Gilleard W, Crosbie J, Smith R. Rising to stand from a chair: symmetry, and frontal and transverse plane kinematics and kinetics. Gait Posture. 2008;27(1):8-15; doi: 10.1016/j.gaitpost.2006.11.002.

20. Cacciatore TW, Gurfinkel VS, Horak FB, Day BL. Prolonged weight-shift and altered spinal coordination during sit-to-stand in practitioners of the Alexander Technique. Gait Posture. 2011;34(4):496-501; doi: 10.1016/j.gaitpost.2011.06.026.

21. Johnson MB, van Emmerik REA. The impact of head orientation on multi-segmental torso coordination during the transition from sitting to standing. Proc Hum Factors Ergon Soc Annu Meet. 2010;54(19):1373-1377; doi: 10.1177/154193121005401904.

22. Johnson MB, Cacciatore TW, Hamill J, van Emmerik REA. Multi-segmental torso coordination during the transition from sitting to standing. Clin Biomech. 2010; 25(3):199-205; doi: 10.1016/j.clinbiomech.2009.11.009.

23. Ikeda ER, Schenkman ML, Riley PO, Hodge WA. Influence of age on dynamics of rising from a chair. Phys Ther. 1991;71(6):473-481; doi: 10.1093/ptj/71.6.473.
24. Schenkman M, Berger RA, Riley PO, Mann RW, Hodge WA. Whole-body movements during rising to standing from sitting. Phys Ther. 1990;70(10):638-648; discussion 648-651; doi: 10.1093/ptj/70.10.638.

25. Kinoshita S, Kiyama R, Yoshimoto Y. Effect of handrail height on sit-to-stand movement. PLoS One. 2015;10(7): e0133747; doi: 10.1371/journal.pone.0133747.

26. Kim SH, Park KN, Kwon OY, Choi HS. Effects of taping the lower back on the lumbopelvic region and hip joint kinematics during sit-to-stand. Phys Ther Korea. 2014;21(4):49-55; doi: 10.12674/ptk.2014.21.4.049.

27. Leardini A, Biagi F, Merlo A, Belvedere C, Benedetti MG. Multi-segment trunk kinematics during locomotion and elementary exercises. Clin Biomech. 2011;26(6):562571; doi: 10.1016/j.clinbiomech.2011.01.015.

28. Park SY, Yoo WG. Effect of wearing a tight waist belt on the sagittal kinematics of the pelvis during sit-to-stand. J Phys Ther Sci. 2014;26(3):435-436; doi: 10.1589/ jpts.26.435.

29. Nuzik S, Lamb R, VanSant A, Hirt S. Sit-to-stand movement pattern. A kinematic study. Phys Ther. 1986;66(11): 1708-1713; doi: 10.1093/ptj/66.11.1708.

30. Maykut JN, Taylor-Haas JA, Paterno MV, DiCesare CA, Ford KR. Concurrent validity and reliability of $2 \mathrm{~d}$ kinematic analysis of frontal plane motion during running. Int J Sports Phys Ther. 2015;10(2):136-146.

31. Selfe J. Validity and reliability of measurements taken by the Peak 5 motion analysis system. J Med Eng Technol. 1998;22(5):220-225; doi: 10.3109/03091909809 032546.

32. Payton CJ, Bartlett RM (eds.). Biomechanical evaluation of movement in sport and exercise: the British Association of Sport and Exercise Sciences Guide. J Sports SciMed.2008;7(1):194; doi:10.4324/9780203935750.

33. Schenkman M, Riley PO, Pieper C. Sit to stand from progressively lower seat heights - alterations in angular velocity. Clin Biomech. 1996;11(3):153-158; doi: 10.1016/ 0268-0033(95)00060-7.

34. Nagamachi M. Ergonomic aspects for assisting facilities to elderly people. Gerontechnology. 2014;13(2):70; doi: 10.4017/gt.2014.13.02.216.00.

35. Shepherd RB, Koh HP. Some biomechanical consequences of varying foot placement in sit-to-stand in young women. Scand J Rehabil Med. 1996;28(2):79-88.

36. Munton JS, Ellis MI, Wright V. Use of electromyography to study leg muscle activity in patients with arthritis and in normal subjects during rising from a chair. Ann Rheum Dis. 1984;43(1):63-65; doi: 10.1136/ard. 43.1.63.

37. Bohannon RW. Reference values for the five-repetition sit-to-stand test: a descriptive meta-analysis of data from elders. Percept Mot Skills. 2006;103(1):215-222; doi: 10.2466/pms.103.1.215-222.

38. Etnyre B, Thomas DQ. Event standardization of sit-tostand movements. Phys Ther. 2007;87(12):1651-1666; doi: 10.2522/ptj.20060378. 
39. Lara J, Cooper R, Nissan J, Ginty AT, Khaw KT, Deary IJ, et al. A proposed panel of biomarkers of healthy ageing. BMC Med. 2015;13:222; doi: 10.1186/s12916-015-0470-9.

40. Kuo YL, Tully EA, Galea MP. Skin movement errors in measurement of sagittal lumbar and hip angles in young and elderly subjects. Gait Posture. 2008;27(2):264270; doi: 10.1016/j.gaitpost.2007.03.016.

41. Turcot K, Armand S, Fritschy D, Hoffmeyer P, Suvà D. Sit-to-stand alterations in advanced knee osteoarthritis. Gait Posture. 2012;36(1):68-72; doi: 10.1016/j.gaitpost.2012.01.005.

42. Antoniolli A, Candotti CT, Gelain GM, Schmit EFD, Ducatti LMA, de Oliveira Melo M, et al. Influence of feet position on static postural assessment by means of photogrammetry: a comparative study. Eur J Physiother. 2018;20(1):1-6; doi:10.1080/21679169.2018.1435719. 